\title{
Thermal properties of AIN polycrystals obtained by pulse plasma sintering method
}

\author{
Paweł J. RUTKOWSKI*, Dariusz KATA \\ Department of Ceramics and Refractories, Faculty of Materials Science and Ceramics, AGH University of Science \\ and Technology, al. Mickiewicza 30, 30-059 Krakow, Poland
}

Received: January 10, 2013; Revised: March 18, 2013; Accepted: March 24, 2013

CThe Author(s) 2013. This article is published with open access at Springerlink.com

\begin{abstract}
Aluminum nitride (AIN) polycrystals were prepared by pulse plasma sintering (PPS) technique. The starting AlN powder mixtures were composed with $3.0 \mathrm{wt} \%, 5.0 \mathrm{wt} \%$ and $10 \mathrm{wt} \%$ of yttrium oxide $\left(\mathrm{Y}_{2} \mathrm{O}_{3}\right)$, respectively. Relative density of each polycrystal was measured by hydrostatic method and evaluated higher than 97\%. X-ray diffraction (XRD) method was used for phase examination of the samples after heat treatment. Microstructure examination supported by computer-aided analysis was performed by scanning electron microscopy (SEM) and energy dispersive spectrometry (EDS). The results were correlated with thermal conductivity of the samples carried out by laser pulse method (LFA). The influence of the rapid sintering technique and yttrium oxide additive content on the thermal conductivity and microstructure appearance of AlN polycrystals was clearly shown.
\end{abstract}

Keywords: aluminum nitride (AlN); thermal conductivity; microstructure; thermal diffusivity; specific heat

\section{Introduction}

Aluminum nitride (AlN) is considered as a challenging material for structural and functional applications, because it has a very high thermal conductivity among other ceramic compounds. In the form of monocrystal or polycrystal, AlN is used in electronic devices, thus squeezing out conventional materials like $\mathrm{SiO}_{2}, \mathrm{Al}_{2} \mathrm{O}_{3}$ or $\mathrm{BeO}$, which are harmful for human body [1,2]. AlN is applied for sensors and heat exchangers to improve their sensitivity and efficiency [3]. Due to its thermal properties, it is also used in arms industry as a part of

\footnotetext{
* Corresponding author.
}

E-mail: pawelr@agh.edu.pl high-power and high-resolution radars [4]. The thermal conductivity $(\lambda)$ of polycrystalline AlN mainly depends on the level of oxygen content dissolved in the crystallographic structure, microstructure appearance and nature of points and linear defects. These factors can radically reduce $\lambda$ from $320 \mathrm{~W} /(\mathrm{m} \cdot \mathrm{K})$ to $70 \mathrm{~W} /(\mathrm{m} \cdot \mathrm{K})$ [5] unless they are controlled well at every stage of manufacturing procedure [6]. Preparation of dense AlN polycrystals requires the addition of liquid phases for sintering. Commercially, $\mathrm{MgO}, \mathrm{CaO}$ or rare-earth metal oxides are used, but the most promising addition is yttrium oxide $\left(\mathrm{Y}_{2} \mathrm{O}_{3}\right)$ resulting in the highest value of thermal conductivity. AlN grains are usually covered by thin layers of alumina $\left(\mathrm{Al}_{2} \mathrm{O}_{3}\right)$; therefore, during sintering, yttrium oxide forms several compounds with alumina, e.g., YAP $\left(\mathrm{YAlO}_{3}\right), \mathrm{YAG}$ $\left(\mathrm{Y}_{3} \mathrm{Al}_{5} \mathrm{O}_{12}\right)$ and $\mathrm{YAM}\left(\mathrm{Y}_{4} \mathrm{Al}_{2} \mathrm{O}_{9}\right)$. The garnet formation 
promotes densification process but additionally leads to the removal of oxygen from AlN structure at temperatures above $1750{ }^{\circ} \mathrm{C}$ [7]. This is related to improving thermal conductivity and density of the polycrystals. The introduction of liquid phases is associated with grain growth and decreasing in concentration of grain boundaries to improve thermal properties [8]. An effective method of preparation AlN polycrystals having higher $\lambda$ is pressureless sintering; however, it needs a long time of heat treatment, usually $2 \mathrm{~h}$ at $1800{ }^{\circ} \mathrm{C}[9,10]$.

The aim of this study is to obtain AlN samples by a rapid densification process-pulse plasma sintering (PPS, modification of SPS (spark plasma sintering)). The literature about such preparation of AlN polycrystals is rather limited. Therefore, the results given below fulfill this gap and make good starting points for further scientific discussion.

\section{Materials and methods}

To produce AlN sinters, commercially available AlN powders (H.C. Starck GmbH, Germany) were used. The powder morphology observed by scanning electron microscopy (SEM, Nova NANOSEM 200 from FEI), and grain size distribution measured with laser diffraction method in alcohol environment (Mastersizer 2000 of Melvern Intruments) are shown in Figs. 1 and 2, respectively. It is detected that the average size of grains is $1.7 \mu \mathrm{m}$, which confirms $D_{50}$ in the range of $0.8-1.8 \mu \mathrm{m}$ taken from the company's analysis. Yttrium oxide produced by the same company having medium-sized grains of $0.8 \mu \mathrm{m}$ was added to prepare mixtures for sintering.

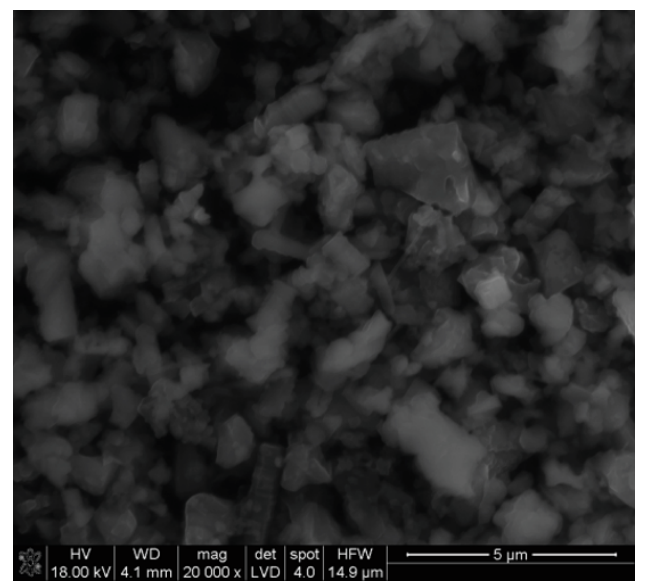

Fig. 1 Morphology of commercial AlN powders.

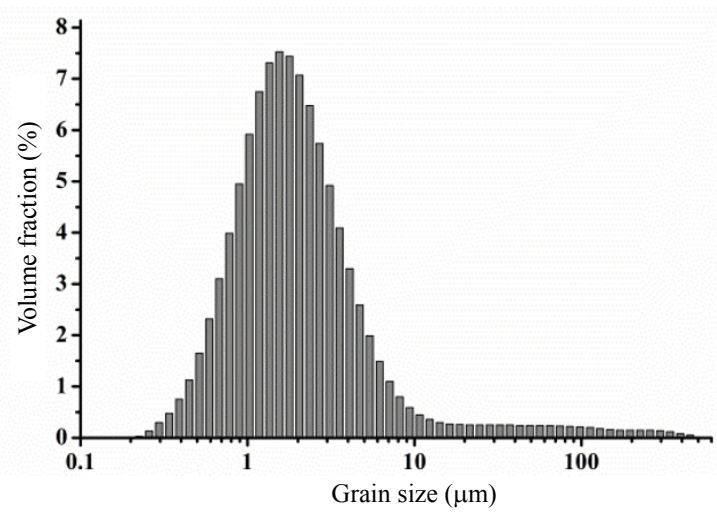

Fig. 2 Grain size distribution of commercial AIN powders.

AlN powders were mixed with $3.0 \mathrm{wt} \%, 5.0 \mathrm{wt} \%$ and $10 \mathrm{wt} \%$ of $\mathrm{Y}_{2} \mathrm{O}_{3}$. The mixtures were homogenized in isopropyl for $24 \mathrm{~h}$ by silicon nitride grinding media. The as-prepared powders were granulated and compacted in carbon mould, and then sintered by PPS in nitrogen flow [11]. The heating rate of $170{ }^{\circ} \mathrm{C} / \mathrm{min}$ was associated with the pressure of $81 \mathrm{MPa}$. The maximum temperature of $1500{ }^{\circ} \mathrm{C}$ was dwelled for $600 \mathrm{~s}$. The apparent density of the sintered AIN was measured using hydrostatic method, and compared to the theoretical density calculated on the base of X-ray diffraction (XRD) analysis. The phase composition of AIN polycrystals was qualitatively and quantitatively examined by XRD method. The thermal measurements were performed by Netzsch LFA 427 apparatus. The thermal diffusivity and specific heat were determined by laser pulse method (LFA) at temperatures from $25{ }^{\circ} \mathrm{C}$ to $600{ }^{\circ} \mathrm{C}$ in step of $100{ }^{\circ} \mathrm{C}$ in argon flow with "Cape-Lehmann + pulse correction" computational model. The thermal expansion coefficient was measured by a Netzsch DIL 402C dilatometer at temperature range from $20{ }^{\circ} \mathrm{C}$ to $600{ }^{\circ} \mathrm{C}$. The thermal conductivity was calculated on the base of the above measured thermal properties. All the samples were polished and then mechano-chemically etched to reveal microstructure details. Microstructure observation was performed by SEM. The grain size of the sintered materials was estimated on SEM images with computer-aided analysis-Aphelion Image Processing Programme.

\section{Results and discussion}

The relative density and phase composition of AlN 
polycrystals are summarized in Table 1. All the samples' relative densities exceed $97 \%$, and two phases are detected in the XRD patterns, i.e., AlN and $\mathrm{Y}_{2} \mathrm{O}_{3}$ garnets. Increasing quantity of $\mathrm{Y}_{2} \mathrm{O}_{3}$ in starting mixtures leads to higher concentration of YAP and YAM phases. Reaction between $\mathrm{Al}_{2} \mathrm{O}_{3}$ originated from grain surface and $\mathrm{Y}_{2} \mathrm{O}_{3}$ leads to the formation of garnets during sintering. It is associated with the decreasing concentration of oxygen in AlN structure resulting in higher thermal conductivity of the obtained polycrystals. It is shown that a short time of heat treatment, e.g., $600 \mathrm{~s}$, and low temperature are enough to prepare full dense AIN polycrystals by PPS technique.

LFA-measured values of specific heat, thermal diffusivity and thermal conductivity of the polycrystals are collected in Table 2. The highest $\lambda$ is achieved for the samples with $5 \mathrm{wt} \%$ of yttrium oxide. All the polycrystals have rather good thermal conductivity ranging from $78 \mathrm{~W} /(\mathrm{m} \cdot \mathrm{K})$ to $100 \mathrm{~W} /(\mathrm{m} \cdot \mathrm{K})$ at $25{ }^{\circ} \mathrm{C}$. However, these results are not as high as those of pressureless sintered AlN [10,12]. This is due to a very fine microstructure of the obtained samples and high concentration of intergranular boundaries. Other concentrations of yttrium oxide dopant $(3 \mathrm{wt} \%$ and $10 \mathrm{wt} \%$ ) cause lower thermal conductivity. In the case for $3 \mathrm{wt} \%$ of yttrium oxide addition, AlN structure contaminated by oxygen is a plausible cause of lower thermal conductivity. On the other hand, the increased porosity of AlN polycrystals sintered with $10 \mathrm{wt} \%$ of yttrium oxide is a reason of lower $\lambda$ compared to $5 \mathrm{wt} \%$ of yttrium oxide content.

Table 1 Relative density and phase composition of polycrystalline AIN

\begin{tabular}{ccccccc}
\hline \multirow{2}{*}{$\mathrm{Y}_{2} \mathrm{O}_{3}$ addition (wt\%) } & \multirow{2}{*}{ Apparent density (\%) } & \multicolumn{5}{c}{ Phase composition (wt\%) } \\
\cline { 3 - 6 } & & AlN & YAG & YAP & YAM & Gamma AlON \\
\hline 3.0 & 99.9 & 94.5 & 5.0 & - & - & 0.5 \\
5.0 & 97.9 & 91.2 & 5.8 & 3.0 & - & - \\
10 & 97.2 & 87.1 & - & 6.3 & 6.6 & - \\
\hline
\end{tabular}

Table 2 Thermal properties of AIN sinters with various additions of yttrium oxide

\begin{tabular}{|c|c|c|c|c|c|c|c|c|c|}
\hline \multirow{2}{*}{ Temperature $\left({ }^{\circ} \mathrm{C}\right)$} & \multicolumn{3}{|c|}{ Thermal diffusivity $\left(\mathrm{mm}^{2} / \mathrm{s}\right)$} & \multicolumn{3}{|c|}{ Specific heat $(\mathrm{J} /(\mathrm{g} \cdot \mathrm{K}))$} & \multicolumn{3}{|c|}{ Thermal conductivity $(\mathrm{W} /(\mathrm{m} \cdot \mathrm{K}))$} \\
\hline & $3 \mathrm{wt} \%$ & $5 \mathrm{wt} \%$ & $10 \mathrm{wt} \%$ & $3 \mathrm{wt} \%$ & $5 \mathrm{wt} \%$ & $10 \mathrm{wt} \%$ & $3 \mathrm{wt} \%$ & $5 \mathrm{wt}^{\%} \%$ & $10 \mathrm{wt} \%$ \\
\hline 25 & 27.9 & 31.7 & 30.7 & 0.84 & 0.94 & 0.92 & 78.8 & 100.1 & 93.8 \\
\hline 100 & 22.3 & 25.0 & 24.2 & 0.99 & 1.14 & 1.10 & 71.1 & 93.5 & 87.1 \\
\hline 200 & 17.8 & 19.0 & 18.7 & 1.10 & 1.24 & 1.19 & 65.3 & 81.5 & 76.5 \\
\hline 300 & 14.8 & 15.8 & 15.3 & 1.32 & 1.49 & 1.43 & 61.6 & 72.1 & 67.5 \\
\hline 400 & 12.8 & 13.5 & 13.0 & 1.28 & 1.45 & 1.39 & 59.6 & 64.8 & 60.1 \\
\hline 600 & 10.0 & 10.5 & 10.1 & 1.33 & 1.52 & 1.46 & 56.6 & 53.3 & 49.4 \\
\hline
\end{tabular}

For the obtained sinters, thermal expansion coefficients (CTE) are measured. CTE values for the temperature range of $40-600{ }^{\circ} \mathrm{C}$, are estimated to $5.72 \times 10^{-6}\left({ }^{\circ} \mathrm{C}\right)^{-1}, 5.41 \times 10^{-6}\left({ }^{\circ} \mathrm{C}\right)^{-1}$ and $5.54 \times 10^{-6}\left({ }^{\circ} \mathrm{C}\right)^{-1}$ with $3 \mathrm{wt} \%, 5 \mathrm{wt} \%$ and $10 \mathrm{wt} \% \mathrm{Y}_{2} \mathrm{O}_{3}$, respectively. The various additions of sintering aid do not influence significantly on thermal expansion of AIN. These results are similar to the literature data [13].

The microstructure appearance of AIN samples are shown in Figs. 3-5. They are very similar in shape of grains for each content of yttrium oxide dopant. Two phases are clearly visible. The grey fields are corresponded to pure AlN grains and light spots are attributed to yttrium-containing phases. EDS examination shown in Fig. 3 and XRD analysis indicate the formation of YAG at grain boundary for the sample containing $3 \mathrm{wt} \%$ of yttrium oxide dopant. It can be concluded that a short time of rapid densification by PPS gives good crystallized garnet phase located at grain boundary. This phase is distributed uniformly at all images shown in Figs. 3-5.

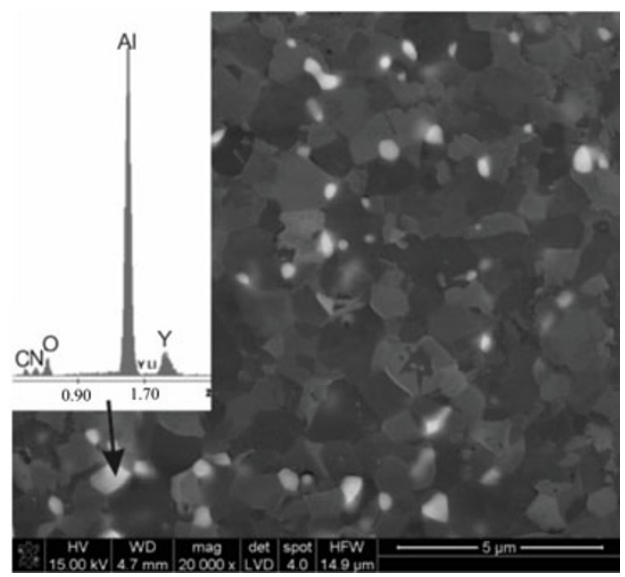

Fig. 3 Microstructure of sintered AlN polycrystals (3 wt $\% \mathrm{Y}_{2} \mathrm{O}_{3}$, sintered at $1500{ }^{\circ} \mathrm{C}$ for $600 \mathrm{~s}$ ). 


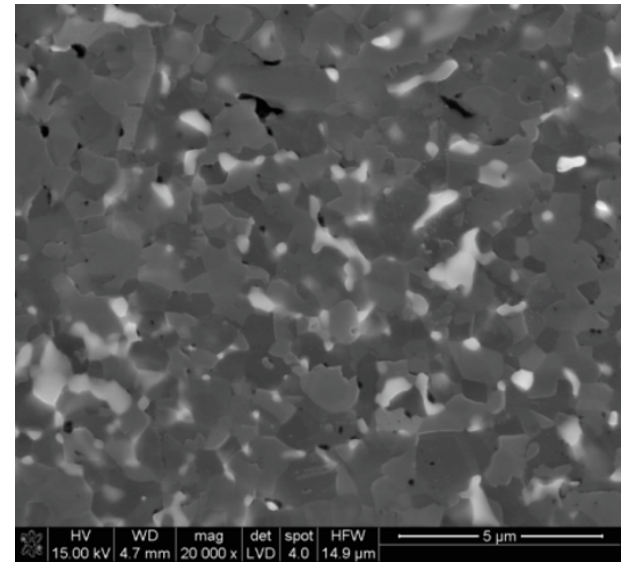

Fig. 4 Microstructure of sintered AlN polycrystals (5 wt $\% \mathrm{Y}_{2} \mathrm{O}_{3}$, sintered at $1500{ }^{\circ} \mathrm{C}$ for $600 \mathrm{~s}$ ).

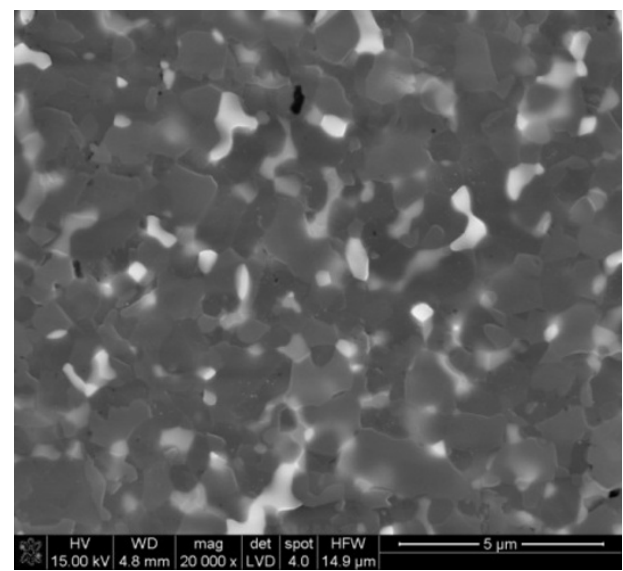

Fig. 5 Microstructure of sintered AIN polycrystals (10 wt $\% \mathrm{Y}_{2} \mathrm{O}_{3}$, sintered at $1500{ }^{\circ} \mathrm{C}$ for $600 \mathrm{~s}$ ).

To calculate grain size distribution, the image shown in Fig. 4 is binarized (Fig. 6) and then examined by computer-aided analysis. $40 \%$ of the grains have an average grain size estimated to $1.0 \mu \mathrm{m}$ as shown in Fig. 7. This value is similar to that of the initial powders, and thus it is concluded that grain growth does not occur during PPS process significantly. For other microstructures, the results are very similar; thus we believe that the amount of yttrium oxide dopant does not control AlN microstructure appearance sintered by PPS. The difference in thermal conductivity of the samples can be explained by porosity changes or specific YAG, YAM or YAP formation. This reaction can reduce the oxygen content inside AlN grains, and therefore each sample has different thermal conductivity. The obtained thermal results for lower temperature sintered polycrystals (PPS) are similar to SPS-sintered materials [14], whose authors used maximum $3 \mathrm{wt} \%$ various additive mixtures $\left(\mathrm{Sn}_{2} \mathrm{O}_{3}-\mathrm{Li}_{2} \mathrm{O}-\mathrm{Y}_{2} \mathrm{O}_{3}\right)$. However, AlN polycrystals described in the present work were prepared at lower temperature of about $250{ }^{\circ} \mathrm{C}$.

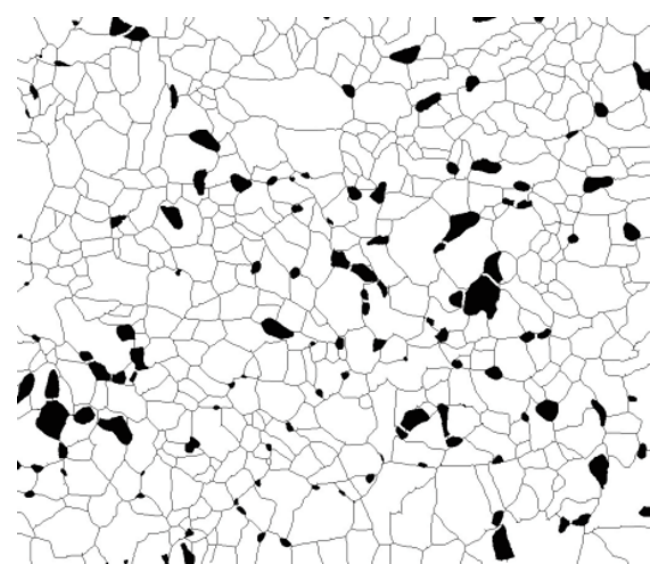

Fig. 6 Binary microstructure image of sintered AlN polycrystals $\left(5 \mathrm{wt} \% \mathrm{Y}_{2} \mathrm{O}_{3}\right.$, sintered at $1500{ }^{\circ} \mathrm{C}$ for $\left.600 \mathrm{~s}\right)$.

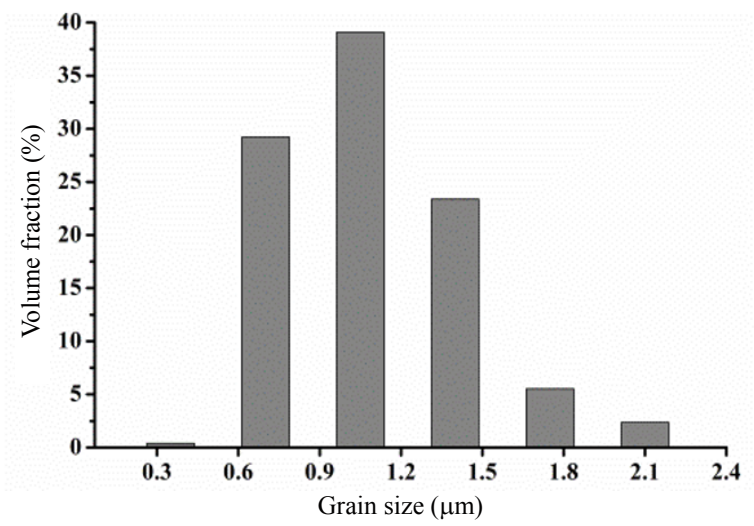

Fig. 7 Grain size distribution of sintered AlN polycrystals $\left(5 \mathrm{wt} \% \mathrm{Y}_{2} \mathrm{O}_{3}\right.$, sintered at $1500{ }^{\circ} \mathrm{C}$ for $\left.600 \mathrm{~s}\right)$.

\section{Conclusions}

It is possible to obtain dense polycrystals of AlN by PPS method at temperature of $1500{ }^{\circ} \mathrm{C}$ in a very short time. The obtained AlN polycrystals are characterized with high density (above 97\%) and good thermal properties. All the samples have fine microstructure with grain size estimated to $1.0 \mu \mathrm{m}$, which can have an influence on the mechanical property improvement. The thermal conductivity of AIN sinters is comparable to polycrystals prepared by SPS method.

\section{Acknowledgements}

The research work was carried out within the project "New Construction Materials with High Thermal 
Conductivity" (No. UDA-POIG.01.01.02-00-97/09-01). Thermal conductivity measurements were performed in collaboration with Faculty Laboratory of Thermophysical Measurements of Materials Science and Ceramics Faculty, AGH University of Science and Technology in Krakow. Materials were obtained in collaboration with Laboratory of Warsaw University of Technology. Thanks to Dr. Lukasz Ciupinski from Faculty of Materials Science and Engineering, Warsaw University of Technology, for sample sintering by PPS process, and to Kamil Jankowski from Faculty of Material Science and Ceramics, AGH University of Science and Technology, for powder mixture preparation.

Open Access: This article is distributed under the terms of the Creative Commons Attribution Noncommercial License which permits any noncommercial use, distribution, and reproduction in any medium, provided the original author(s) and source are credited.

\section{References}

[1] Baik K, Drew RAL. Aluminum nitride: Processing and applications. Key Eng Mat 1996, 122-124: 553-570.

[2] Axelbaum RL, Lottes CR, Huertas JI, et al. Gas-phase combustion synthesis of aluminum nitride powder. Twenty-Sixth Symposium (International) on Combustion/The Combustion Institute, 1996: 1891-1897.

[3] Campbell CK. Applications of surface acoustic and shallow bulk acoustic wave devices. Proc IEEE 1989, 77: $1453-1484$.
[4] Tiegs TN, Kiggans Jr. JO. High thermal conductivity lossy dielectric using codensified multilayer configuration. U.S. Patent 6579393, June 2003.

[5] Rutkowski P, Kata D. The influence of aluminum nitride polycrystal annealing time on its thermal conductivity. Ceram Mater 2013, 65 (in Polish, in press).

[6] Komeya K, Tatami J. Liquid phase sintering of aluminum nitride. Mater Sci Forum 2007, 554: 181-188.

[7] Jankowski K, Kata D, Lis J. Preparation of polycrystalline aluminum nitride with yttria additive. Ceram Mater 2012, 64: 214-218 (in Polish).

[8] Jackson TB, Virkar AV, More KL, et al. High-thermal-conductivity aluminum nitride ceramics: The effect of thermodynamics, kinetics and microstructural factors. J Am Ceram Soc 1997, 80: $1421-1435$.

[9] $\mathrm{Xu} \mathrm{GF}$, Olorunyolemi $\mathrm{T}$, Wilson $\mathrm{OC}$, et al. Microwave sintering of high-density, high thermal conductivity AlN. J Mater Res 2002, 17: 2837-2845.

[10] Rutkowski P, Kata D, Lis J. Thermal conductivity of polycrystalline AlN. Ceram Mater 2012, 64: 572-576 (in Polish).

[11] Michalski A. Pulse plasma sintering of ceramics materials. Ceramics 2005, 91: 379-385.

[12] Bellosi A, Esposito L, Scafè E, et al. The influence of microstructure on the thermal conductivity of aluminum nitride. J Mater Sci 1994, 29: 5014-5022.

[13] Craft S, Moody B, Dalmau R, et al. Thermal expansion engineering for polycrystalline aluminum nitride sintered bodies. U.S. Patent 2012/0146023 A1, June 2012.

[14] Li MJ, Zhang LM, Shen Q, et al. Microstructure and properties of spark plasma sintered AlN ceramics. J Mater Sci 2006, 41: 7934-7938. 